\title{
Acoustic characterization of seafloor habitats on the western continental shelf of India
}

Bishwajit Chakraborty, Vasudev Mahale, Gajanan Navelkar, B. Ramalingeswara Rao, R. G. Prabhudesai, Baban Ingole, and G. Janakiraman

Chakraborty, B., Mahale, V., Navelkar, G., Rao, B. R.,. Prabhudesai, R. G., Ingole, B., and Janakirinam, G. 2007. Acoustic characterization of seafloor habitats on the western continental shelf of India. - ICES Journal of Marine Science, 64(3): 551-558.

This is a study of the interaction effects of the dual frequency (210 and $33 \mathrm{kHz}$ ) backscatter signal with seafloor sediment and benthic biota along a transect in water 27-83 m deep offshore of the Goa region of India's central west coast. Estimation of the power law exponent using seafloor topographic data provided equivalent values even when using dual high-frequency systems for different grain-size sediments. Backscatter signals corrected from system-related gain, etc., reveal better correlations with sedimentary and benthic parameters than the estimated coherence parameters (using echo peaks). Statistically, correlations are significant for the $210 \mathrm{kHz}$ backscatter signal with sand and calcium carbonate $\left(\mathrm{CaCO}_{3}\right)$ sediment content. Also, correlations are higher for macrobenthic biomass (wet weight) and population density with a $210 \mathrm{kHz}$ backscatter strength, emphasizing the dominant seawater-seafloor interface scattering process. For $33 \mathrm{kHz}$ backscatter strength, the absence of such correlations indicates a different scattering processes, i.e. dominant sediment volume scattering attributable to the comparatively lower signal attenuation. Additionally, to validate the results, the backscatter signal from other locations in the vicinity of this transect were considered.

Keywords: backscatter strength, benthic habitats, echo peaks, seafloor classifications, sediment grain size.

B.Chakraborty, V. Mahale, G. Navelkar, B. R. Rao, R. G. Prabhudesai, and B. Ingole: National Institute of Oceanography, Dona Paula, Goa: 403 004, India. G. Janakiraman, National Institute of Ocean Technology, Velachery, Tambaram Road, Chennai: 601 302, India. Correspondence to B. Chakraborty: tel: +91 8322450 450, fax: +91 8322450 602/603: e-mail bishwajt@nio.org. 


\section{Introduction}

Understanding sound-signal characteristics from the seafloor is very complicated because of variations in the physical parameters at different scales. For seafloor characterization, the vertical incidence beam of an echosounding system has long been recognized as a useful profiling tool (Pace, 1983). Parameters such as sediment grain size, surface relief at the water-sediment interface, and variations within the sediment matrix generally control the sound-signal scattering. Studies using multi-parameter-based scattering models have been employed for seafloor classification and characterization, using the echo-peak probability density function (Rice PDF). Rice PDF-based studies provide mixed results for coarser seafloor sediments (sand and silty sand), but for finer seafloor sediments (clayey silt and clays), classification is difficult (Chakraborty and Pathak, 1999). However, currently developed temporal models (Pouliquen and Lurton, 1982) utilizing echo envelopes are successful for certain specific data sets, although these models may not produce reliable results for dominant biogenic or anisotropic seafloor sediments, which may require further stringent approximations (Sternlicht and de Moustier, 2003). In order to develop the most general quantitative model, a rigorous understanding of the physical relationship among processes (environmental) and properties (acoustic, electrical and mechanical) being developed at the high frequency ranges of the acoustic signals (Thorsos and Richardson, 2002) is required. Specifically, such a quantitative model must include such processes as sediment-habitat interactions (Richardson and Bryant, 1996) and the effect of seafloor calcium carbonate contents on backscatter signals (Davis et al., 1996) for remote sediment characterizations. This means that regional seafloor backscatter and sediment data acquisition in several areas is needed for effective model development.

Earlier work involving Rice PDF studies from three locations of the western Indian continental shelf between Mangalore and Kochi provided information on seafloor microtopographic roughness at $12 \mathrm{kHz}$ (Chakraborty et al., 2001). This work extends the detailed data acquisition activity of January 2005 (Anon., 2005) in the shelf region off Marmugao (Figure 1) with a dual-frequency (210 and 33 $\mathrm{kHz}$ ) vertical beam echo-sounding envelope exercise with surface sediment sample collection at seven locations (1-7), covering finer clays and coarser sands. The importance of benthic production is known in this part of the study area (Parulekar, 1976; Parulekar et al., 1982; Ingole et al., 2002), and it allowed us to check the effect on the dual acoustic-signal frequencies attributable to benthic habitats. Further, estimation of the quantitative biomass and population density of benthic habitats at these seven locations was carried out using sediment samples. We wish to present the statistical relationship between the acoustic signal backscatter parameters and certain environmental parameters of geological and biological importance on this central western Indian continental shelf. In addition, we acquired dual-frequency backscatter signals and sediment samples from seven other locations (8- 
14) in the vicinity (Figure 1). This was done to validate the results obtained from the seven locations along the main transect. Echo data sets for the present study were acquired from flat topography; within the shelf area considered for this study the slope is less than $0.5^{\circ}$ (Rao and Wagle, 1997). The ship’s speed was very slow ( $\sim 1$ knot) during data acquisition.

\section{Material and methods}

\section{Data acquisition and the survey area}

A Reson Navitronic NS-420 dual-frequency, single-beam echosounder was utilized for this exercise. The raw analogue output on the receiver circuit board was tapped and connected to a PCL-1712L 12bit A/D card installed on a personal computer (PC) with a sampling rate of $1 \mathrm{MHz}$. The echo data from locations 1-14 (Figure 1) were acquired at frequencies of 210 and $33 \mathrm{kHz}$, with 1000 sounding pings each. As the receiving window is considered to be $40 \mathrm{~ms}$, each snapshot received consisted of 40000 sample data points from the normal-incidence beam echoes. The echo-waveform data acquired through an A/D card are binary in nature, and are converted to ASCII format within the range -5 to +5 V. We employed a two-step data-cleaning method: first, removal of the saturated or clipped waveforms, and second, removal of the waveforms showing inconsistent echo-energy values within the particular location data. The second step was carried out after employing a Hilbert transform to obtain the echo envelope, which is again suitably down-sampled to 200 points within the range $0-5 \mathrm{~V}$. Our data processing is detailed by Navelkar et al. (2005). Examples of the dual-frequency echo envelopes are shown in Figure 2. However, few pings were acquired from location 7 using the $33 \mathrm{kHz}$ signal, so that location is not utilized in the analysis. Detail of the data-acquisition methods are also given in Chakraborty et al. (2005). Sound-signal penetration and attenuation into the seabed is different between the 210 and the $33 \mathrm{kHz}$ frequencies. The received echo length for $33 \mathrm{kHz}$ is $3-4$ times more than for $210 \mathrm{kHz}$ in this data set.

The survey area is located off Marmugao $\left(15^{\circ} 10^{`} \mathrm{~N} 73^{\circ} 10^{`} \mathrm{E}\right.$ to $\left.15^{\circ} 40^{`} \mathrm{~N} 73^{\circ} 55^{`} \mathrm{E}\right)$, and the survey was conducted aboard the coastal research vessel (CRV) "Sagar Purvi" along the track shown in Figure 1. The single-beam $33 \mathrm{kHz}$ bathymetry data along the transect and at seven stations was logged by GPS onto the PC through a serial port, using a hyper-terminal. Simultaneously, Reson 8101 (240 $\mathrm{kHz}$ ) multi-beam, echosounder data were acquired for mapping the seafloor. The raw bathymetry data files after manual cleaning were put into grids using spline-interpolation (grid cell size $10 \mathrm{~m}$ ), in order to plot contour maps and to extract depth profiles using Geographical Mapping Tools (GMT) (Douds, 1998). This evenly spaced depth profile was then used to estimate the Power Spectral Density (PSD) of the grid's bathymetric data. Also, PSD estimation was carried out over the depth profile obtained from the hyper-terminal-logged data $(33 \mathrm{kHz})$ (Figure 3a). Applying the power law expression for 
curve fitting over the PSD provides the spectral slopes. Non-significantly different power law exponent parameters for two frequencies were 1.89 and 1.92, respectively, for the 240 and $33 \mathrm{kHz}$ depth profiles, which indicate an even seafloor along the transect with different sediment grain size (Figure 3b, c).

During the cruise, ground-truth samples were collected by grab at all locations where echo data acquisitions were made. The surface-sediment samples were analysed by pipette methods (Folk, 1968) for grain-size information in terms of sand, silt, and clay percentages, and the calcium carbonate content was determined using a Karbonate bomb (Table 1). Analyses of benthic habitats were carried out based on Holme and McIntyre (1984). Sediment samples from locations 1-7 for benthic studies were acquired during the CRV “Sagar Sukti” cruise of February 2005. Table 1 lists the results by station for macrobenthos also. However, the population density data in silty sand sediments showed extremely high values for bivalves, 1194.4 per $\mathrm{m}^{2}$, out of a total value of $2189.44 \mathrm{~m}^{2}$ at location 2. The estimated biomass at location 2 was of the order of $7.96 \mathrm{~g} \mathrm{~m}^{-2}$. The biomass at location 3 with silty sand sediments was similar, but population density was very low. Low values of population density and biomass were found comparatively fine-grained silty clay sediments at locations 4, 6, and 7 (Table 2). No direct relationship among biota and sediment grain size could be drawn when comparing with the backscatter echo data of the two frequencies (Tables 1, 2). Therefore, statistical analysis was required to determine the extent of the relationships with acoustic-signal backscatter and benthic habitat.

\section{Coherence parameter estimation}

We estimated the coherence parameter $(\gamma)$ of the echo peak of the acquired waveform data. The term $\gamma$ is defined as a ratio between the coherently reflected and the incoherently scattered echo energy. The Rice PDF of the echo peak amplitude $e$ from the seabed is described (Stanton, 1984) as

$$
P(e)=\left[2 e(1+\gamma) /<e^{2}>\right] * \exp \left\{-\left[(1+\gamma) e^{2}+\gamma<e^{2}>\right] /<e^{2}>\right\} I_{0}(q) .
$$

The term $q$ in the modified Bessel function $I_{0}(q)$ can be expressed as

$$
q=2 e[\gamma(1+\gamma)]^{0.5} /\left(<e^{2}>\right)^{0.5}
$$

The expected value of the echo-peak squared is denoted by $\left\langle e^{2}>\right.$, and $\gamma$ is the measure of the relative roughness or smoothness of the seafloor, i.e. the coherence parameter. The Rice PDF is expressed 
with respect to $\gamma$, which is used to fit the histograms of the echo peaks. The echo-peak data so obtained from the envelope data are used to draw the histograms for each location.

In order to determine $\gamma$ for the different areas, a moment method based upon Talukdar and Lawing (1991) is applied. We define a new variable $y^{\prime}=e / \sqrt{ }\left\langle e^{2}\right\rangle$ and use it in Equation (1). The first moment $(\mu)$ of the Rice PDF is expressed in terms of $\gamma$ and $y^{\prime}$ as

$$
\mu=<y^{\prime}>=\left\{\Gamma(3 / 2) /(1+\gamma)^{0.5}\right\} * \exp (-\gamma / 2)\left[(1+\gamma) I_{0}(\gamma / 2)+\gamma I_{1}(\gamma / 2)\right]
$$

In Equation (3), $\mu$ varies between $\sqrt{ } \pi / 2$ (Rayleigh PDF, $\gamma=0$ ) and 1 (Gaussian PDF). The mean value of the peak data set is normalized with the second moment of the echo-peak data, and is compared with the theoretical mean $(\mu)$, using Equation (2) to estimate $\gamma$. Using the estimated $\gamma$ value in Equation (1), well-matched PDF curves can be plotted (Figure 4).

\section{Backscatter data processing}

In order to compute backscatter strength from the raw backscatter signal of the dual- beam echosounder, we followed Urick (1967), as referenced in Greenlaw et al. (2004) and Sternlicht and de Moustier (2003):

$<10 * \log _{10} S>=<20 * \log _{10} U_{A}>-\mathrm{V}_{\text {tot }}-$ Gup $-\mathrm{SL}+<40 * \log _{10}(R)>+2 * \alpha_{b} * \mathrm{R}-10 * \log _{10} A$,

where $S$ is backscatter strength, $U_{A}$ the raw backscatter signal obtained from particular locations, and $V_{\text {tot }}$ is system gain and operator gain utilized in the echosounder. For the source level (SL) and receiving sensitivity (Gup), two different sets of values were used for two frequencies, i.e. 210 and 33 $\mathrm{kHz}$. Similarly, for the attenuation coefficient $\left(\alpha_{b}\right)$, two values corresponding to 210 and $33 \mathrm{kHz}$ were used. Here, $R$ is the vertical depth in metres and $A$ is the beam-insonified area. For a circular beam towards the normal incidence direction with a longer pulse period, $A=\pi r^{2}$. Here, $r$ is the radius of the footprint, which is a function of beam width and vertical distance. The computed values of backscatter strength $(\mathrm{dB})$ are presented with respect to echo length. However, although echo data were acquired for an echo length of $0.04 \mathrm{~s}$, we employed an adaptive method to determine the actual window length and computed backscatter strength for the two operating frequencies. We selected $10 \%$ of the highest peak value as a threshold level to identify the initial and final endpoints of the data window for the receiving envelope waveform. When analysing the data, we used the echo-waveform envelopes with 
numerous distinct peaks: we did not employ an averaging technique to smooth the data, as other workers have done.

\section{Results and discussion}

\section{Coherence parameter results using peak PDF}

The data points in Figure 4 represent the experimental echo-peak PDFs, and the curves describe the theoretical PDFs for the 210 and $33 \mathrm{kHz}$ frequencies, respectively. We know that the scattering phenomenon is dependent on the sound-signal operating frequency, which is relatively dominant for $210 \mathrm{kHz}$ rather than for the $33 \mathrm{kHz}$ signal. In $210 \mathrm{kHz}$ signal data from location 1, which has coarser sediments and very high $\mathrm{CaCO}_{3}$ content, and locations 5 and 6 , with fine grain sediments, the $\gamma$ values are comparatively low, whereas for mixed type sediment at locations 2 and 3, the $\gamma$ values are high (Table 1). Stanton and Clay (1986) show that for the same seafloor, if the $\gamma$ values at a particular operating frequency are known, then we can predict $\gamma$ values for any other frequency. Accordingly, at the $33 \mathrm{kHz}$ operating frequency, the $\gamma$ value is expected to have higher values than the corresponding $210 \mathrm{kHz}$ frequency for the same seafloor, and we observe this in our estimated $\gamma$ values (except at location 3). However, we found irregular $\gamma$ values for the $33 \mathrm{kHz}$ operating frequency owing to its higher penetration ability. Therefore, $\gamma$ values cannot be predicted correctly, especially when there is a complex seafloor system where surface and immediately subsurface sediments are dominant with varying grain size, $\mathrm{CaCO}_{3}$ content, and benthic habitats. The results of the model study using echopeak PDF data show some interesting seafloor roughness parameters, when employing Rice PDFbased models. However, there was no significant correlation among the estimated coherence parameters for two operating frequencies for different seafloor locations (Tables 1 and 3).

\section{Backscatter}

For the $210 \mathrm{kHz}$ frequency there is clear distinction between the first three locations in their coarser sand and silty sand sediments and their relatively clayey sediment in terms of backscatter strength and received pulse length (Figure 5a). However, the backscatter strength and pulse lengths are higher at locations 1 and 2, which contain sand and silty sand with $\mathrm{CaCO}_{3}$ content of 91\% and 75.3\%, respectively. The relatively higher backscatter strength and low pulse length at location 3 may be attributed to the reduced $\mathrm{CaCO}_{3}$ content of sediments (41.6\%) there. Backscatter strengths were higher and the spread of received pulse lengths relatively wide for the three coarse/mixed-grain sediments. This indicates a dominant but fluctuating scattering phenomenon in the coarse/mixed-grain sediment locations, especially those with high $\mathrm{CaCO}_{3}$ content. Moreover, there were distinct 
clustering patterns among coarse/mixed and fine-grain seafloor sediments (low backscatter strength and well compressed receiving pulse length). The mean backscatter strengths of $210 \mathrm{kHz}$ signals are lower (around 6-14 dB) for fine-grain, silty clay sediments than the coarse/mixed-grain sandy and silty sand sediments. This difference is similar to that found by Davis et al. (1996) for a frequency of $100 \mathrm{kHz}$. However, $33 \mathrm{kHz}$ data in this study provide no clear clustering pattern between backscatter strength (Table 1) and received pulse lengths for locations 1-7 (Figure 5b). No significant variation in backscatter strength was obtained for $33 \mathrm{kHz}$ signal data for various sediment regimes (Table 1). This result is completely different from that of the $210 \mathrm{kHz}$ data set, in which interface (seawater-seafloor) scattering is dominant. For $33 \mathrm{kHz}$ backscatter signal, sediment volume scatter is a major contributor because of its comparatively low attenuation coefficient, i.e. higher penetration ability. Unlike 210 $\mathrm{kHz}$, no clear difference is seen in backscatter values between the coarser and fine-grained seafloor sediment.

Qualitative comparison between backscatter strength and habitat details (e.g. population density and biomass) reveals a different view about echosounder operating frequencies (Table 2). Apart from statistical data for the habitats, Table 2 provides details about the species from the locations 2, 3, 4, 6, and 7. Interestingly, in the case of the $210 \mathrm{kHz}$ frequency, the backscatter strength in coarse/mixedgrain sediments is directly controlled by macrobenthic groups such as bivalves and gastropods. However, polychaetes are found at almost all locations. The backscatter strength is generally low, particularly for fine-grain sediments with less biomass of dominant polychaetes. There is no distinct relationship among population density and backscatter strength for the $210 \mathrm{kHz}$ frequency. For the 33 $\mathrm{kHz}$ signal, backscatter strengths are generally stronger than for the $210 \mathrm{kHz}$ signal, but there is no relationship between backscatter strength and biomass/population density of a species.

\section{Correlation analysis}

Jackson et al. (1996) established the usefulness of statistical techniques in understanding the spatial and temporal dependence of benthic differences via backscatter signals. In this study, we employ correlation statistics to acoustic backscatter data in order to understand the processes involved. The correlation coefficients were computed for each station from the backscatter strengths and estimated coherence parameters with respect to available environmental parameters such as sediment grain size (sand, silt and clay percentages), $\mathrm{CaCO}_{3}$ (\%), benthic biomass, and population density. Table 3 provides details of the results in matrix form for locations 1-7. The correlation coefficients were significantly high for backscatter-strength data at $210 \mathrm{kHz}$. Very high correlation coefficients were obtained for sand sediment (0.90), and $\mathrm{CaCO}_{3}$ content (0.75), results indicative of the dominant processes at the seawater-seafloor interface. Owing to its high attenuation coefficient, the penetration ability of a $210 \mathrm{kHz}$ signal is limited. Interestingly, the correlation coefficient obtained between the 
$210 \mathrm{kHz}$ signal backscatter strength and $\mathrm{CaCO}_{3}$ content are similar to the results presented by Davis et al. (1996) for $100 \mathrm{kHz}$, i.e. their 0.67 vs. our 0.75. Moreover, good correlation between backscatter signal and benthic biomass (0.91) and population density (0.58) indicate significant correlation between surficial benthic habitats and the related $210 \mathrm{kHz}$ backscatter strength, especially at sandy and silty-sand sediment locations. Correlation coefficients for the coherence parameter $(\gamma)$ and other environmental parameters for the $210 \mathrm{kHz}$ signal are average. As already mentioned, coherence parameters are computed using only the echo peaks of the signals and compared with backscatter strength for which the entire echo envelope is used. Correlation results for average backscatter strength (entire envelope) would be expected to be better than when echo-peak levels are used for estimation.

For the $33 \mathrm{kHz}$ signal, there were good correlations only for sediments having high silt (0.68) and clay (0.75) content, and correlations were poor for benthic population density (0.09) and negative for biomass. The lower correlation values obtained with $33 \mathrm{kHz}$ are indicative of different scattering phenomena than when $210 \mathrm{kHz}$ signal data are applied. As already mentioned, the $33 \mathrm{kHz}$ signal has the higher volume scattering effect because of its greater penetration ability than $210 \mathrm{kHz}$. At $210 \mathrm{kHz}$ signal levels, moderate to high correlations for benthic population density and biomass indicate the existence of appreciable sizes of benthic habitats at the seawater-seafloor interface.

Earlier, we presented data along the transect of seven locations (Figure 1, Table 1). However, in order to validate these results we also include the results from seven other locations (8-14) in the vicinity of the transect (see Figure 1). However, the coherence parameters of these data sets were not computed because of their insignificant correlations with sediment and benthic parameters. Owing to the non-availability of benthic data from locations 8-14, we do not have population density and biomass parameters for correlation studies. To investigate the interrelationships among estimated backscatter strength and sediment grain-size distribution, we present correlation coefficients in Table 3. Those correlation coefficients relate to the operational frequency applied. Correlations were good for $210 \mathrm{kHz}$ backscatter signals for parameters such as sand (0.83) and $\mathrm{CaCO}_{3}$ content (0.74), but coefficients are negative for silt and clay. For the $33 \mathrm{kHz}$ backscatter signal, the estimated correlation coefficients were negative for coarser sand and $\mathrm{CaCO}_{3}$ content at locations 1-7. However, correlation was poor for silty and clay (0.28) sediments. Generally, the $33 \mathrm{kHz}$ backscatter signal had better penetration ability, so may be encountering different subsurface sediment layer compositions at locations $1-7$, although the surface sediments are the same. The sediment grain-size information provided for this study is based on the top sediment surface acquired by a grab, so cannot be used for subsurface layers of sediment. 
Table 3 also summarizes the correlation coefficients between backscatter strength and sediment grain size and $\mathrm{CaCO}_{3}$ content at all 14 locations. Correlation coefficients are high for $\mathrm{CaCO}_{3}(0.64)$ and sand (0.76) content for the $210 \mathrm{kHz}$ signal, whereas for silt and clay sediments correlations were negative. For the $33 \mathrm{kHz}$ backscatter signal, there are weak correlations only for silt (0.09) and clay (0.36) content. In general, the correlation results presented in Table 3 are similar for the $210 \mathrm{kHz}$ signal and all sediment types, but the $33 \mathrm{kHz}$ signal encountered different sediment environments because of its better signal-penetration capability.

\section{Overview}

We have attempted to identify interrelationships between various seafloor parameters in terms of backscatter-echo signal data acquired using a dual-frequency, single vertical-beam echosounder on the continental shelf of the Arabian Sea off western India (near Marmugao). Similar power-law exponent parameters are obtained using seafloor topographic data for two frequencies (33 kHz and $210 \mathrm{kHz}$ ). Tapped dual frequency ( $210 \mathrm{kHz}$ and $33 \mathrm{kHz}$ ) echosounder peak data were used for Rice PDF-based studies to estimate the coherence parameter from a transect. They do not show any regular variations with respect to the seafloor sediment or habitat parameters. However, in order to incorporate a correction into backscatter strength, system-related gain parameters were utilized. Presentation in Figure 5 of the computed backscatter strengths within the reverberation window (allowing a threshold of $10 \%)$ provides two distinct patterns between coarse and fine-grain sediments for the $210 \mathrm{kHz}$ backscatter signal. Such patterns were not observed for the $33 \mathrm{kHz}$ backscatter signal, differences that can be attributed to the greater signal penetration capability of the $33 \mathrm{kHz}$ signal and the dominance of the volume scattering from the sediment. For the $210 \mathrm{kHz}$ signal, the seawater-seafloor interface scattering was dominant. Using two operating frequencies for a similar area of seafloor, the dominance of two different scattering processes was clear. Statistical relationships among signal parameters (backscatter strengths and coherence parameters using echo peaks), along with sediment grain size and benthic habitats (population density and biomass), indicate obvious relationships among sediment grain size and benthic habitat through correlations between backscatter strength and estimated coherence, using echo peaks. Correlation percentages were very high between the $210 \mathrm{kHz}$ backscatter signal and the $\mathrm{CaCO}_{3}$ and sand sediment content. There was also a clear correlation between the $210 \mathrm{kHz}$ backscatter signal and benthic biomass and population density. These positive correlation values for the $210 \mathrm{kHz}$ backscatter signal with sediment and macrobenthos affirm the dominance of seawater-seafloor interface scattering. For the $33 \mathrm{kHz}$ backscatter signal, there were no regular relationships between backscatter and sediment or macrobenthos. This is due to the existence of top-layer sediment characteristics such as sand and $\mathrm{CaCO}_{3}$ for coarse/mixed-grain sediment. A similar existence of surficial, i.e. interface between seawater and seafloor, benthic biomass and 
population density indicates poor correlation with the $33 \mathrm{kHz}$ backscatter signal, which indirectly reflects the dominance of the volume-scattering process. Attempts to validate the correlation results between backscatter signal and sediment parameters during the transect by use of other backscatter data sets acquired from adjacent locations at the same time strongly support the statistical relationship we found.

\section{Acknowledgements}

We thank S. R. Shetye, Director of the NIO, for his encouragement and permission to publish this work, the Director, NIOT, Chennai, for vessel support, and Shri Padmanathan for assistance. Financial support (GAP 1493) was obtained from the Department of Information Technology (DIT), New Delhi, India. Finally, we thank Van Holliday of BAE Systems for his encouragement, and an anonymous reviewer for useful suggestions on our draft manuscript, which is NIO contribution 4212.

\section{References}

Anon. 2005. “Sagar Purvi” cruise report, 03/05. NIOT, Chennai. 12 pp.

Chakraborty, B., and Pathak, D. 1999. Seabottom backscatter studies in the western continental shelf of India. Journal of Sound and Vibration, 219: 51-62.

Chakraborty, B., Kaustubha, R., Hegde, A., and Pereira, A. 2001. Acoustic seafloor sediment classification using self organizing feature maps. IEEE Transactions on Geoscience Remote Sensing. 38: 2722-2725.

Chakraborty, B., Navelkar, G., Prabhudesai, R. G., Janakiraman, G., Mahale, V., Fernandez, W., and Rao, N. 2005. Echo-waveform classification using model and model-free techniques: experimental study results from central western continental shelf of India. In Proceedings of the IEEE MTS. Washington DC.

Davis, K. S., Slowey, N. C., Stender, I. H., Fiedler, H., Bryant, W. R., and Fechner, G. 1996. Acoustic backscatter and sediment textural properties of inner shelf sands, northeastern Gulf of Mexico. Geo-Marine Letters, 16: 273-278.

Douds, A. S. B. 1998. Fractal analysis of topography and structure across the Appalachian foreland of West Virginia. MS thesis, University of West Virginia. 115 pp.

Folk, R. L. 1968. Petrology of Sediment Rocks. Hemphills, Austin, Texas. 177 pp.

Greenlaw, C., Holliday, D. V., and McGehee, D. E. 2004. High-frequency scattering from saturated sand sediments. Journal of the Acoustical Society of America, 115: 2818-2813.

Ingole, B. S., Rodrigues, N., and Ansari, Z. A. 2002. Macrobenthic communities of the coastal waters of Dhabol, west coast of India. Indian Journal of Marine Science. 31: 93-99.

Jackson, D. R., Williams, K. L., and Briggs, K. B. 1996. High-frequency acoustic observations of benthicspatial and temporal variability. Geo-Marine Letters. 16: 212-218. 
Navelkar, G., Prabhudesai, R. G., and Chakraborty, B. 2005. Dual-frequency, echo-data acquisition system for seafloor classification. In Proceedings of the National Symposium on Ocean Electronics. pp. 42-48. Allied Publishing. New Delhi. 309 pp.

Pace, N. G. 1983. Acoustic classification of seabed. In CRC Handbook of Geophysical Exploration at Sea, pp. 211-218. Ed. by R. A. Geyer. CRC Press, Boca Raton, Florida.

Parulekar, A. H. 1976. Benthos of the Arabian Sea. Journal of the Indian Fisheries Association. 6: 1-10.

Parulekar, A. H., Harkantra, S. N., and Ansari, Z. A. 1982. Benthic production and assessment of demersal fishery resources of the Indian Seas. Indian Journal of Marine Science. 11: 107-114.

Pouliquen, E., and Lurton, X. 1992. Sea-bed identification using echosounder signals. In Proceedings of the 1st European Conference on Underwater Acoustics, pp. 535-538. Ed. by M. Weydert. Elsevier, London. 764 pp.

Rao, V. P., and Wagle, B. G. 1997. Geomorphology and surficial geology of the western continental shelf of India: a review. Current Science, 73: 330-349.

Richardson, M. D., and Bryant, W. R. 1996. Benthic boundary-layer processes in coastal environments: an introduction. Geo-Marine Letters, 16: 133-139.

Stanton, T. K. 1984. Sonar estimates of seafloor micro-roughness. Journal of the Acoustical Society of America, 77: 809-818.

Stanton, T. K., and Clay, C. S. 1986. Sonar echo-statistics as a remote sensing tool: volume and seafloor. IEEE Journal of Oceanic Engineering, 11: 79-96.

Sternlicht, D., and de Moustier, C. 2003. Time-dependent, seafloor acoustic backscatter (10-100 kHz). Journal of the Acoustical Society of America, 114: 2709-2725.

Talukdar, K. K., and Lawing, W. D. 1991. Estimation of the parameters of the Rice distribution. Journal of the Acoustical Society of America, 89: 1093-1107.

Thorsos, E. I., and Richardson, M. D. 2002. Guest Editorial. IEEE Journal of Oceanic Engineering, 27: 341344.

\section{Figure legends}

Figure: 1. Survey area and data-acquisition locations.

Figure 2. Echo-envelope data for (a) and (b) the 33kHz signal, and (c) and (d) the $210 \mathrm{kHz}$ signal for sandy and clay sediments, respectively.

Figure 3. (a) Depth profiles from the $33 \mathrm{kHz}$ single-beam echosounder, and $240 \mathrm{kHz}$ multi-beam grid data and sampling locations ( $y$-axis exaggeration, $500 \times$ ). Power Spectral Density (PSD) plotted against wave number for the (b) the $210 \mathrm{kHz}$ and (c) the $33 \mathrm{kHz}$ profile.

Figure 4. (a) $210 \mathrm{kHz}$ and (b) $33 \mathrm{kHz}$ echo-peak Probability Density Function (PDF) and Rice PDFs (dashed line and asterisks, PDF data; solid line and + signs, Rice PDF).

Figure 5. Backscatter Strength $(\mathrm{dB})$ plotted against receiving echo-window length for seven locations for (a) the $210 \mathrm{kHz}$ signal and (b) the $33 \mathrm{kHz}$ signal (red, green, blue, light blue, magenta, yellow, and black indicate locations $1-7$, respectively). 
Table 1. Dual-frequency backscatter strength and coherence parameters, sediment grain size, and benthic habitat at the study locations.

\begin{tabular}{|c|c|c|c|c|c|c|c|c|c|c|c|}
\hline \multirow{2}{*}{ Location } & \multirow{2}{*}{$\begin{array}{l}\text { Depth } \\
\text { (m) }\end{array}$} & \multicolumn{2}{|c|}{$\begin{array}{c}\text { Backscatter } \\
\text { strength (dB) } \\
\end{array}$} & \multicolumn{2}{|c|}{$\begin{array}{c}\text { Coherence } \\
\text { parameter }(\gamma)\end{array}$} & \multicolumn{4}{|c|}{ Sediment content (\%) } & \multicolumn{2}{|c|}{ Benthic habitat } \\
\hline & & $\begin{array}{c}33 \\
\mathbf{k H z} \\
\end{array}$ & $\begin{array}{c}210 \\
\mathrm{kHz}\end{array}$ & $\begin{array}{c}33 \\
\mathbf{k H z} \\
\end{array}$ & $\begin{array}{r}210 \\
\text { kHz } \\
\end{array}$ & Sand & Silt & Clay & $\mathrm{CaCO}_{3}$ & $\begin{array}{c}\text { Density } \\
\left(\text { no. } \mathrm{m}^{-2}\right)\end{array}$ & $\begin{array}{c}\text { Biomass } \\
\left(\mathrm{g} \mathrm{m}^{-3}\right)\end{array}$ \\
\hline 1 & 83.52 & -31.72 & -32.60 & 10 & 09 & 94.0 & 00.0 & 06.0 & 91.00 & - & - \\
\hline 2 & 75.56 & -28.17 & -32.13 & 31 & 15 & 68.7 & 17.5 & 13.7 & 75.30 & 2189 & 7.96 \\
\hline 3 & 66.73 & -30.92 & -30.46 & 09 & 20 & 77.0 & 15.0 & 08.0 & 41.66 & 597.0 & 7.49 \\
\hline 4 & 52.39 & -27.85 & -44.47 & 21 & 16 & 02.2 & 45.0 & 52.8 & 17.30 & 199.9 & 1.59 \\
\hline 5 & 42.00 & -26.31 & -38.74 & 11 & 08 & 02.7 & 40.0 & 57.3 & 10.00 & - & - \\
\hline 6 & 32.65 & -27.52 & -38.78 & 27 & 08 & 00.7 & 15.0 & 84.3 & 10.00 & 577.7 & 3.87 \\
\hline 7 & 27.48 & -28.72 & -40.51 & - & 09 & 01.2 & 40.0 & 58.8 & 10.00 & 796.1 & 0.062 \\
\hline 8* & 24.00 & -24.43 & -34.18 & - & - & 02.5 & 25.0 & 72.5 & 05.0 & - & - \\
\hline $9 *$ & 34.62 & -27.75 & -34.99 & - & - & 01.4 & 45.0 & 53.6 & 05.0 & - & - \\
\hline $10 *$ & 56.04 & -26.01 & -36.74 & - & - & 01.5 & 45.0 & 53.5 & 08.0 & - & - \\
\hline $11^{*}$ & 62.28 & -33.62 & -34.47 & - & - & 01.1 & 50.0 & 48.9 & 10.0 & - & - \\
\hline $12 *$ & 85.41 & -38.63 & -34.28 & - & - & 74.0 & 17.5 & 08.5 & 81.3 & - & - \\
\hline $13 *$ & 78.33 & -31.59 & -30.75 & - & - & 93.0 & 02.5 & 04.5 & 64.0 & - & - \\
\hline $14^{*}$ & 76.95 & -21.97 & -29.40 & - & - & 93.3 & 05.0 & 01.7 & 88.0 & - & - \\
\hline
\end{tabular}

* Location data used for validating the results 
Table 2. Species groups analysed, and statistical parameters by location.

\begin{tabular}{|c|c|c|c|c|c|c|c|c|}
\hline \multirow[t]{2}{*}{ Location } & \multicolumn{6}{|c|}{ Species group } & \multirow{2}{*}{$\begin{array}{c}\text { Density } \\
\text { (number) }\end{array}$} & \multirow{2}{*}{$\begin{array}{c}\text { Biomass } \\
\left(\mathrm{g} \mathrm{m}^{-2}\right)\end{array}$} \\
\hline & Nemertenia & Bivalvia & Gastopoda & Polychaeta & Crustacea & Amphipoda & & \\
\hline 2 & 0.0 & 1194.4 & 199.04 & 796.16 & 0.0 & 0.0 & 2189.44 & 7.962 \\
\hline 3 & 0.0 & 199.04 & 99.04 & 99.04 & 0.0 & 0.0 & 597.12 & 7.492 \\
\hline 4 & 0.0 & 22.22 & 0.0 & 155.54 & 22.22 & 0.0 & 199.98 & 1.593 \\
\hline 6 & 88.88 & 0.0 & 0.0 & 488.86 & 0.0 & 0.0 & 577.72 & 3.875 \\
\hline 7 & 0.0 & 0.0 & 0.0 & 796.16 & 0.0 & 0.0 & 796.16 & 0.062 \\
\hline
\end{tabular}

Table 3. Correlation coefficients obtained between backscatter strength at the two frequencies and sediment and benthic parameters for subsets of locations and for all locations.

\begin{tabular}{|c|c|c|c|c|c|c|}
\hline Variable & $\mathrm{CaCO}_{3}(\%)$ & Sand (\%) & Silt (\%) & Clay (\%) & $\begin{array}{l}\text { Density } \\
\left(\text { no. } \mathbf{m}^{-2}\right)\end{array}$ & $\begin{array}{c}\text { Biomass } \\
\left(\mathrm{g} \mathrm{m}^{-3}\right)\end{array}$ \\
\hline \multicolumn{7}{|l|}{ Locations 1-7 only } \\
\hline $\begin{array}{l}\text { Backscatter strength } \\
\text { at } 33 \mathrm{kHz}\end{array}$ & -0.68 & -0.81 & 0.68 & 0.75 & 0.09 & -0.41 \\
\hline $\begin{array}{l}\text { Backscatter strength } \\
\text { at } 210 \mathrm{kHz}\end{array}$ & 0.75 & 0.90 & -0.80 & -0.80 & 0.58 & 0.91 \\
\hline$\gamma$ at $33 \mathrm{kHz}$ & -0.06 & -0.29 & 0.07 & 0.35 & 0.57 & -0.09 \\
\hline $\begin{array}{l}\text { Backscatter strength } \\
\text { at } 33 \mathrm{kHz}\end{array}$ & -0.21 & -0.15 & -0.05 & 0.28 & - & - \\
\hline $\begin{array}{l}\text { Backscatter strength } \\
\text { at } 210 \mathrm{kHz}\end{array}$ & 0.74 & 0.83 & -0.84 & -0.74 & - & - \\
\hline \multicolumn{7}{|l|}{ All locations (1-14) } \\
\hline $\begin{array}{l}\text { Backscatter strength } \\
\text { at } 33 \mathrm{kHz}\end{array}$ & -0.29 & -0.28 & 0.09 & 0.36 & - & - \\
\hline
\end{tabular}




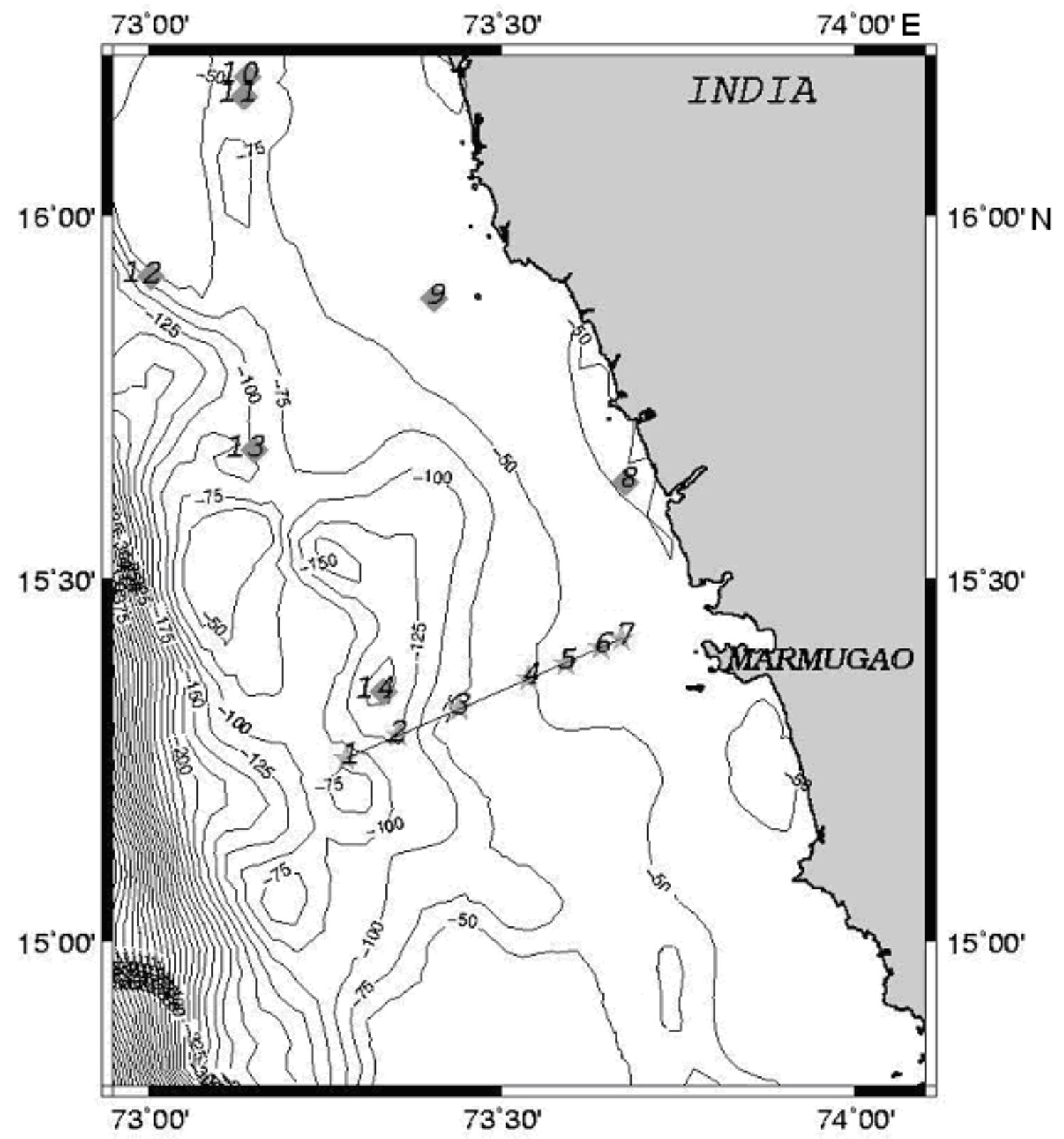

Figure 1 

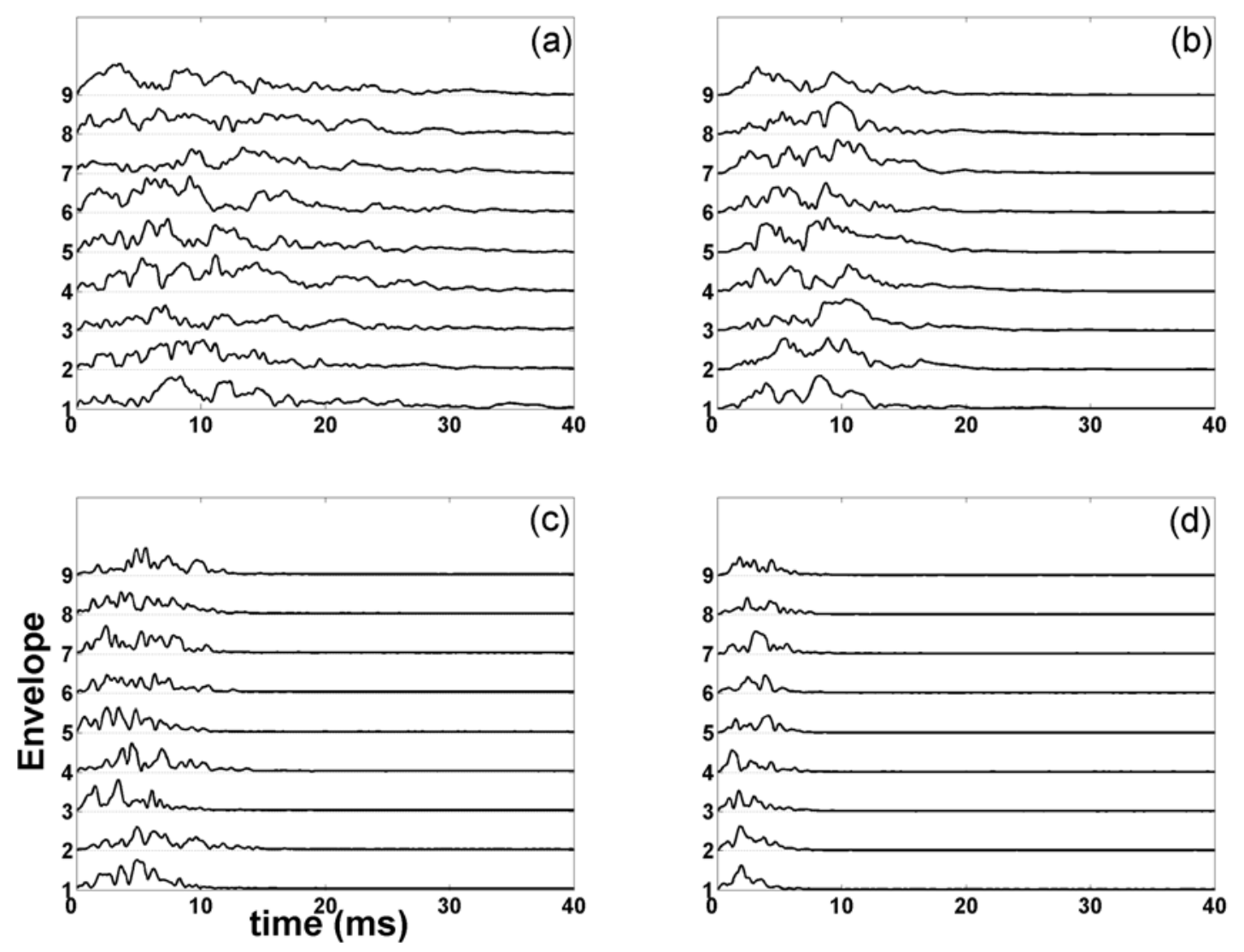

Figure 2 

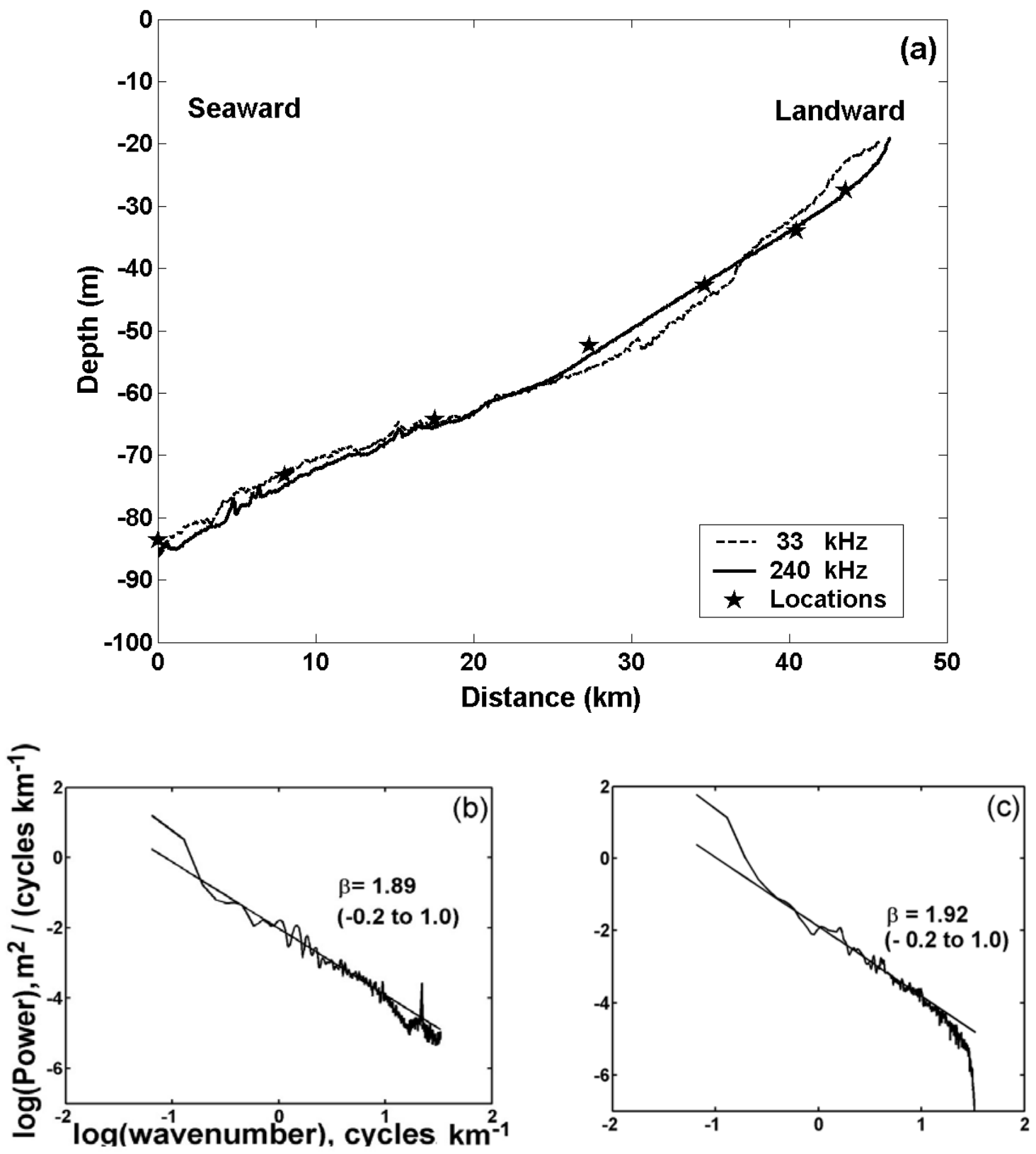

Figure 3 
(a) Probability Density Function (PDF) for $210 \mathrm{kHz}$
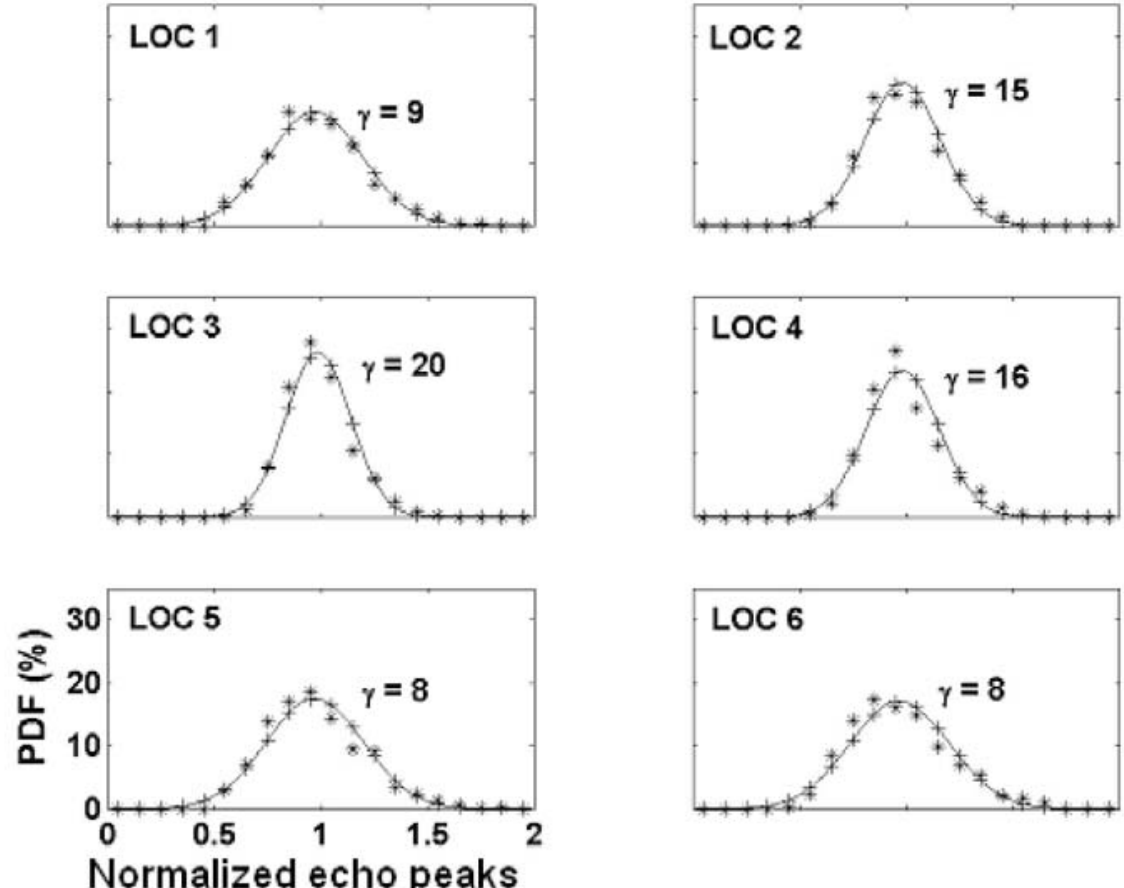

Normalized echo peaks

(b) Probability Density Function (PDF) for $33 \mathrm{kHz}$
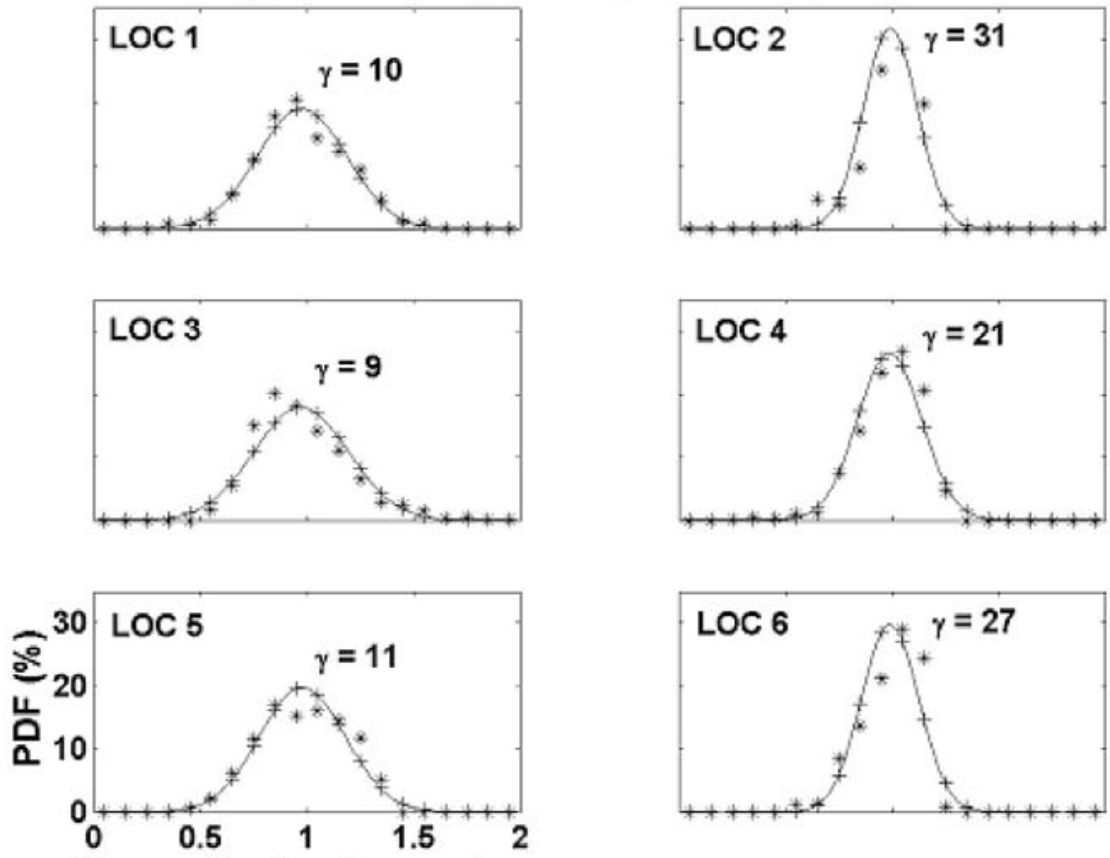

Normalized echo peaks

Figure 4 

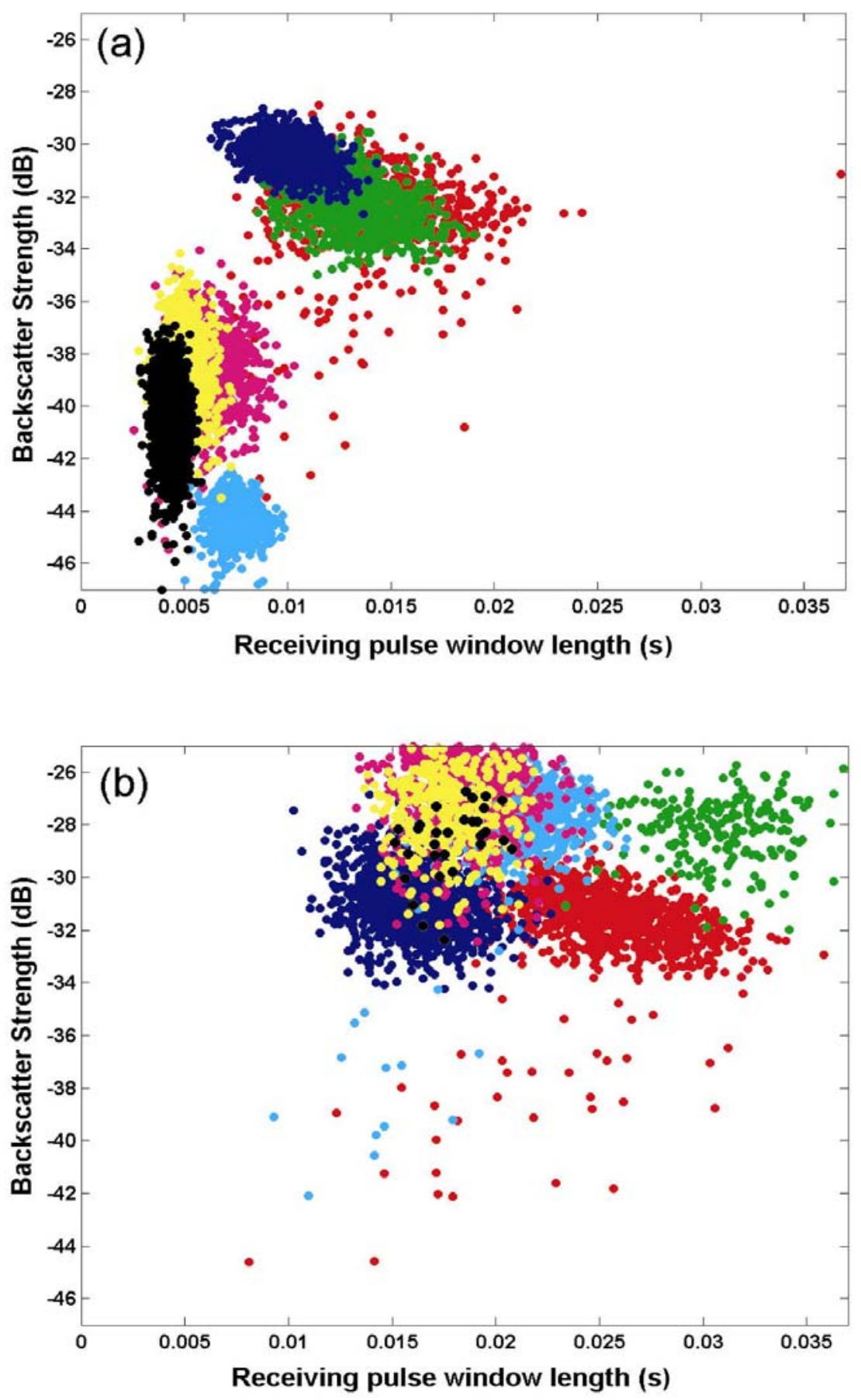

Figure 5 